\title{
Defining Irrigation Set Points Based on Substrate Properties for Variable Irrigation and Constant Matric Potential Devices in Greenhouse Tomato
}

\author{
Isabelle Lemay and Jean Caron ${ }^{1}$ \\ Département des sols et de génie agroalimentaire, Université Laval, 2480 \\ boul Hochelaga, Québec, G1V 0A6 Canada
}

\author{
Martine Dorais \\ Agriculture et Agroalimentaire Canada, Québec, Canada and Département \\ de phytologie, Université Laval, Québec, G1V 0A6, Canada \\ Steeve Pepin \\ Département des sols et de génie agroalimentaire, Université Laval, 2480 \\ boul Hochelaga, Québec, G1V 0 A6 Canada
}

Additional index words. peat, sawdust, growing media, aeration, organic waste, oxygen, tensiometer, water potential, Solanum lycopersicum

\begin{abstract}
Ongoing research on organic growing media for greenhouse tomato production is driven by the constant changes in the quality, stability, and form of the organic byproducts used in the manufacturing of these media. This study was undertaken to determine appropriate irrigation set points for a sawdust-peat mix (SP) under development given that the performance of this substrate appeared to be strongly dependent on appropriate irrigation management. A greenhouse tomato experiment was conducted to compare different irrigation management approaches for a SP substrate in the spring and summer. Using preliminary measurements from an initial experiment (Expt. 1), different irrigation strategies for the SP substrate were compared in a second experiment (Expt. 2): 1) a variable irrigation regime using a timer control (with frequency adjusted as a function of irradiance); 2 ) tensiometer control at $-1.5 \mathrm{kPa}$; and 3 ) two constant substrate water potential devices: $-1.1 \mathrm{kPa}$ and $-0.9 \mathrm{kPa}$. An irrigation timer/controller using solar radiation input was used with a rockwool control (RC) substrate. Measurements of plant activity [photosynthesis rate and stomatal conductance $\left(g_{\mathrm{S}}\right)$, substrate physical and chemical properties, biomass, and yield were obtained. For all irrigation strategies, results indicated that $10 \%$ to $20 \%$ higher photosynthesis rates and $g_{\mathrm{S}}$ values were obtained with the SP substrate compared with RC. Data indicated that moderate drying conditions (matric potential ranging from $-2.2 \mathrm{kPa}$ to $-1.5 \mathrm{kPa}$ in Expt. 1 and Expt. 2, respectively) relative to container capacity $(-0.6 \mathrm{kPa})$ were beneficial for improving plant photosynthetic activity and allowed the highest yields for the SP substrate. Variable irrigation management showed higher levels of plant activity than constant watering and increased the oxygen concentration in the substrate by $\approx 2 \%$ in absolute value relative to the constant water potential device. Lower $\mathrm{CO}_{2}$ and $\mathrm{N}_{2} \mathrm{O}$ levels were also observed with the variable irrigation strategy. On the other hand, maximum nutrient solution savings were achieved with the constant matric potential devices $(8 \%$ to $31 \%$ relative to the RC). This study showed high productivity potential for the SP substrate with suitable irrigation management. Replacing conventional growing media with organic waste-based products using an appropriate irrigation strategy may help to increase the sustainability of the greenhouse industry.
\end{abstract}

\footnotetext{
Received for publication 23 Feb. 2012. Accepted for publication 14 May 2012.

We thank J. Moreau and L. Gaudreau of Serres du St-Laurent and C. Boily from Laval University for their helpful advice as well as S. Descôteaux of Hortau and N. Bertrand of Agriculture and Agri-Food Canada for their technical support. Thanks are extended to the Natural Sciences and Engineering Research Council of Canada and to Agriculture and Agri-Food Canada for their financial contributions and to Les Serres du St-Laurent (Savoura), Hortau, Industries Maibec Inc., and Premier Horticulture Ltd. for supplying equipment and materials.

${ }^{1}$ To whom reprint requests should be addressed; e-mail Jean.Caron@fsaa.ulaval.ca.
}

Maas, 1971, 1976; Haynes and Goh, 1978; Starck and Okruszko, 1984) with the aim of improving the performance and potential use of such media (Morel et al., 2000). Changes in the nature and properties of the byproducts themselves as well as new insights into substrate growth limitations have renewed interest in this avenue of research (Allaire et al., 2005; Bégin, 2008; Juneau et al., 2006). Wood industry byproducts are of particular interest as alternatives to current substrate components. Sawdust and bark are commonly used as substrate material despite the growth limitations identified in previous studies (Bégin, 2008; Dorais et al., 2007; Gruda and Schnitzler, 2004; Morel et al., 2000). In the specific case of wood byproducts like sawdust, restricted growth has been linked to low water availability (Allaire et al., 2005; Desbiens, 2004; Juneau et al., 2006), nutrient immobilization (Kostov et al., 1991), the presence of toxic compounds (Dorais et al., 2007; Kostov et al., 1991; Lemaire et al., 2003), salt accumulation (Desbiens, 2004), and, like in the case of bark, to a lack of oxygen at the rhizosphere level (Caron et al., 2010; Juneau et al., 2006; Naasz et al., 2009). Additionally, growth limitations in very coarse substrate may be the result of poor capillary properties (Caron et al., 2005) and poor contact at the soil-root interface (Örlander and Due, 1986) and consequently low water buffer capacity (Allaire et al., 2005; Desbiens, 2004). In view of these limitations related to water and aeration status, substrates using wood waste materials require an appropriate design, including suitable particle size and precise irrigation management (Bégin, 2008; Dorais et al., 2005).

\section{Improving substrate productivity:}

particle size and irrigation management

Particle size. Substrate particle-size distribution plays an important role in greenhouse productivity of tomato. In a study conducted by Desbiens (2004) on different properties of individual components (peat, bark, sawdust) of various particle-size mixes, pure sieved brown peat ( 0.5 to $6 \mathrm{~mm}, \mathrm{H} 3-\mathrm{H} 4)$ and white spruce sawdust (less than $6 \mathrm{~mm}$ in diameter) were found to be the most promising substitutes for rockwool thanks to their low cost and availability in addition to their excellent growth performance. However, the study concluded that, despite adequate soil physical properties, the low water availability and salt accumulation problems needed to be addressed for sawdust to have full productivity potential. Bégin (2008) and Dorais et al. (2005) showed that adding $30 \%$ wood fiber to sawdust (less than $6 \mathrm{~mm}$ ) growing media improved easily available water (EAW), which reached $0.12 \mathrm{~cm}^{3}$ of water $/ \mathrm{cm}^{3}$ of bulk volume compared with $0.09 \mathrm{~cm}^{3} \cdot \mathrm{cm}^{-3}$ for sawdust without reducing air-filled porosity. Nonetheless, the improvement in EAW had no major effects on tomato plant growth, yield, or fruit quality, although it significantly increased plant water uptake per day and reduced nutrient leaching. Juneau et al. (2006) determined that the addition of $30 \%$ sieved peat (greater than $0.5 \mathrm{~mm}$ and less than $6 \mathrm{~mm}$ ) and 10\% compost (volume 
basis) to $60 \%$ white spruce sawdust (less than $6 \mathrm{~mm}$ ) allowed optimal aeration based on either gas diffusivity or air-filled porosity and provided similar productivity to rockwool. Recently, like Desbiens (2004), Letourneau (2009) found that with sawdust peat-based substrates, irrigation strategies (dripper distribution and number, absence of surface evaporation, volume of leaching) played a key role in the salt build-up process and in subsequent leaching.

Substrate irrigation management. Because environmental policies are becoming much more restrictive and agricultural sustainability improvements are essential to limit environmental burdens, water and nutrient use efficiency, along with reduced leaching, represent key constraints for designing new growing media. In greenhouse production, drippers are mainly used for fruit vegetables such as tomato (Johnstone et al., 2005; Letard et al., 1995; Michelakis and Chartzoulakis, 1988), and irrigation scheduling can be controlled by timers in combination with evapotranspiration estimates or cumulative irradiance levels. Although other parameters can be used such as surface evaporation (Guttormsen, 1974; Mahajan and Singh, 2006), stem diameter (Letard et al., 1995), plant water content, or leaf temperature (Dorais et al., 2005), their use may be timeconsuming and may involve calibration and adjustments, and their performance in terms of productivity often varies according to plant development and climatic conditions (Dorais et al., 2005). Alternatively, measurement of substrate matric potential is a method that has long been available to growers (Frenz and Lechl, 1981; Norrie et al., 1995), but the optimal soil water potential used as the basis for initiating irrigation varies according to substrate physical properties. For peat-based soilless growing media in general, previous studies showed that matric potential of -5 to $-10 \mathrm{kPa}$ limited crop yield for Ficus benjamina L. (De Boodt and de Waele, 1968) and Petunia $\times$ hybrida (Jobin et al., 2004). When comparing an irrigation trigger set point of $-9 \mathrm{kPa}$ relative to $-5 \mathrm{kPa}$, Xu et al. (1995) reported a 6\% decrease in yield for tomato grown in $24 \mathrm{~L}$ of peat and perlite mix (70:30 v/v), whereas Norrie et al. (1995) observed no difference between two matric potential set points $(-4.5$ and $-6.5 \mathrm{kPa})$ in terms of tomato yields obtained in peat-based substrate. Differences in response between different substrates may be the result of differences in their water retention curves, because depending on the shape of this curve, the amount of water left in the material may be small enough that pores are no longer interconnected, causing a decrease in transport below the level required by the plant (Jobin et al., 2004). Alternatively, substrates with high respiration requirements may suffer from wet management (Naasz et al., 2009). Finally, set points may vary with plant consumption, because prolonged periods with high water potential overnight may be detrimental to plant growth by favoring anaerobic conditions, whereas the same threshold may be optimal during the day when plants are actively transpiring.
With regard to recommending a mean targeted matric potential value for triggering irrigation, relevant studies have reported that when yield, photosynthesis, or any other plant activity or productivity index decreases, it is difficult to determine the effect of the fluctuation of water potential about the mean and the effect of the mean value itself. Indeed, with fluctuations of water potential, extended periods of stress may occur (waterlogging or excess drying), whereas none would occur in a constant water potential system, which would be less affected by such stresses. However, the effect may be complex, because in addition to the stress created by temporal waterlogging or wilting conditions, solute and gas distribution within the substrates is likely to be modified because of the important convective fluxes resulting from the extensive water application and rapid drainage processes that occur in a drip irrigation system compared with a constant supply irrigation system such as a capillary mat, in which diffusive gas fluxes dominate (Caron et al., 2002b). Hence, in addition to the mean effect of the mean daily matric potential, variations in the minimum (trigger set point) and maximum (after irrigation) matric potential values associated with an irrigation device or a specific irrigation regime may also have a significant effect on the crop compared with a constant value. Therefore, constant and variable tension devices may affect substrate performance and they deserve to be compared.

Because of the effect that container geometry plays on the distribution of gases and water and their adequate supply to the plant, modifying container geometry is an efficient way to achieve adequate aeration, leaching, and supply of water and nutrient to growing plants. Hence, as a practical solution, container geometry or slab form can be modified to achieve high-performance irrigation and aeration (Bilderback and Fonteno, 1987) and this approach was investigated in some studies (Blok, 1999). In this study, the constant and variable water potential strategies were compared for the sawdust-based medium by using a modified container geometry to ensure adequate capillary rise and aeration despite the application of constant water potential. For nursery plants grown in bark and sphagnum substrates, Caron et al. (2002b) reported improved yield performance when constant supply irrigation devices were used compared with a variable drip irrigation system. However, no study until now has compared the performance of sawdust-based growing media for tomato grown under constant or variable set point thresholds. This aspect of water management is important, because the use of either tensiometer-controlled irrigation or constant head devices has permitted a significant reduction in water use and in nitrate leaching (Juneau et al., 2006; Lieth and Burger, 1989; Waister and Hudson, 1970), which are environmentally beneficial outcomes.

The objectives of this study were to identify appropriate irrigation strategies for a lowcost sawdust-based substrate to 1) achieve optimum plant activity and productivity; and
2) reduce water and fertilizer leaching. The following hypotheses were tested: 1) a constant matric potential (capillary system) gives plant activity (photosynthesis, $g_{\mathrm{S}}$, biomass, and yield) similar to or higher than variable irrigation management based on matric potential thresholds (on/off system); 2) appropriate matric thresholds and a capillary device reduce water and nutrient leaching relative to a timer-based approach adjusted to the irradiance level; and 3) an appropriate irrigation strategy for a sawdust peat substrate improves water use efficiency as well as plant activity and yield compared with a rockwool-grown tomato crop with intermittent irrigation. To achieve these objectives, a first study was conducted at a commercial site to determine the irrigation set points, which were then tested extensively under well-controlled conditions at an experimental site.

\section{Materials and Methods}

\section{Expt. 1: Deriving set points for optimal plant activity within a commercial greenhouse facility}

Derivation of initial irrigation set points was based on the assumption that photosynthesis, growth, and yield are all directly related to substrate water potential (Xu et al., 1995). This initial assumption was later supported by our data (Lemay, 2006). Measurements were taken on mature tomato plants grown in a commercial greenhouse facility in Portneuf (Les Serres du St-Laurent Inc., Québec, Canada, lat. $46^{\circ} 42^{\prime} 39^{\prime \prime} \mathrm{N}$, long. $71^{\circ} 53^{\prime} 5^{\prime \prime} \mathrm{W}$ ) during four different periods and at 3-month intervals throughout a complete year. Tomato plants (Solanum lycopersicum cv. Trust) were grown in a commercial container $41.5 \mathrm{~cm}$ long $x$ $28 \mathrm{~cm}$ wide $\times 13 \mathrm{~cm}$ high (Fig. 1A) filled with sawdust peat growing media $(2: 1 \mathrm{v} / \mathrm{v}$; Bégin, 2008; Dorais et al., 2005) or transplanted to a rockwool slab (Grodan Master Dry type, $50 \mathrm{~cm}$ long $\times 24 \mathrm{~cm}$ wide $\times 10 \mathrm{~cm}$ high). For each sampling period, hourly measurements of $\mathrm{CO}_{2}$ assimilation (net photosynthesis) and $g_{\mathrm{S}}$ were made with a LI-COR LI-6400 (Lincoln, NE) apparatus during draining and rewetting sequences. Matric potential was measured simultaneously with a pressure transducer and tensiometers (Soil Measurement Systems, Tucson, AZ) and the volumetric water content was measured with three $12-\mathrm{cm}$ long stainless steel probes using a time domain reflectometry apparatus (Tektronix 1502C, Corvallis, OR). Measurements were taken between 0900 and 1500 HR during 2 consecutive days on one plant per replicate. The afternoon before measurements, substrates were leached with $10 \mathrm{~L}$ of nutrient solution per slab to remove excess salts, if any, and achieve full slab saturation and drainage. They were rewetted again early in the morning on the day of the measurements to achieve saturation and leaching. For each type of substrate, drippers were removed from three to six replicates until the first signs of wilting occurred to obtain a large range of substrate water status values; they were reinstalled the next day before irrigation events, hence 


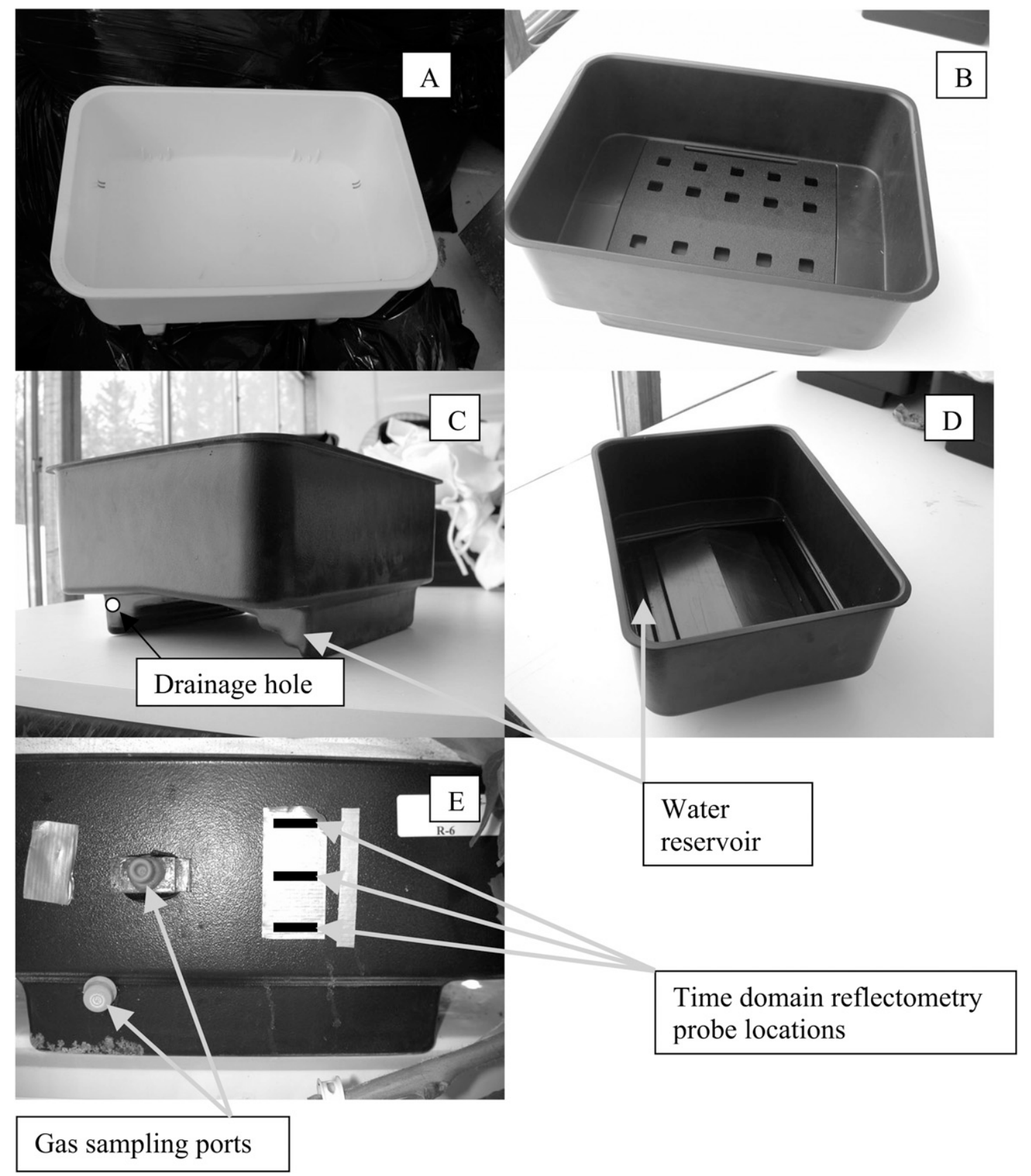

Fig. 1. (A-E) Photography and schematic representation of the containers used and locations of the probes installed for the experiment at the University.

providing a sequence of measurements of draining and rewetting of the substrate over a 2-d period for substrate with and without drippers. A different plant was sampled for each individual measurement of photosynthesis and $g_{\mathrm{S}}$. Maximum values of the two parameters were determined at $0.5-\mathrm{kPa}$ intervals and then plotted as a function of the corresponding matric potential to draw the boundary lines (Webb, 1972) and determine the irrigation set points for both substrates.

\section{Expt. 2: Deriving and testing irrigation} set points within an experimental setup

Irrigation management. To investigate average matric potential value and variable matric potential effects, four irrigation treatments were compared for the SP-based substrate:
1) timer-based irrigation adjusted according to irradiance level (SP/TM);2) tensiometerbased irrigation with set point at $-1.5 \mathrm{kPa}(\mathrm{SP} /$ TS-1.5); and two capillary rise constant water potential devices set to 3$)-1.1 \mathrm{kPa}(\mathrm{SP} / \mathrm{C}-1.1)$ and 4) $-0.9 \mathrm{kPa}(\mathrm{SP} / \mathrm{C}-0.9)$. As for one of the SP treatments, rockwool was irrigated with a timer-based approach adjusted to irradiance level and was used as a control (RW/TM). For the RW/TM and SP/TM treatments, the irrigation volume was the same and was adjusted daily according to the irradiance level (minimum interval of $35 \mathrm{~min}$ with 75 to $150 \mathrm{~mL}$ of applied water per plant every $600 \mathrm{~kJ} \cdot \mathrm{m}^{-2}$ ); the electrical conductivity (EC) of the rockwool treatment was adjusted to avoid an increase in EC and to obtain a $10 \%$ to $30 \%$ leaching fraction. For the matric potential driven treatment
SP/TS-1.5, the irrigation set point, as measured with tensiometers (see section "Measurements and Analysis"), was $-1.5 \mathrm{kPa}$ during the day, and 120 to $300 \mathrm{~mL}$ of water was applied per plant per irrigation event, depending on the irradiance level and the $\mathrm{EC}$ of the substrate. For capillary rise treatments SP/C-1.1 and $\mathrm{SP} / \mathrm{C}-0.9$, the underneath water reservoir was gradually filled in the morning through short irrigation events that induced leaching. From the height of the water accumulating in the bottom reservoir, the leachate fraction could be calculated and duration of irrigation adjusted to reach a $10 \%$ to $30 \%$ leaching fraction at each irrigation event during the day. The maximum amount stored in the reservoir was $190 \mathrm{~mL}$ for $\mathrm{SP} / \mathrm{C}-1.1$ and $830 \mathrm{~mL}$ for SP/C-0.9. By late afternoon, the amount of 
irrigation was reduced to allow the reservoir to empty during the night and to prevent or reduce hypoxia conditions associated with periods when plants are not actively transpiring. This resulted in lower substrate water potential overnight as the substrate became drier. Overnight, $60 \mathrm{~mL}$ per plant were given in treatments SP/TS-1.5, SP/C-0.9, and SP/C-1.1 whenever the matric potential reached $-2.0 \mathrm{kPa}$. The day and night matric potentials maintained in the different treatments were as follows: -0.61 and $-1.05 \mathrm{kPa}$ for RW/TM; -0.91 and -1.49 for SP/TM; -1.19 and -1.63 for SP/TS-1.5; -1.09 and -1.62 for SP/C-1.1; and -0.92 and $-1.52 \mathrm{kPa}$ for SP/C-0.9.

The treatments began in mid-March and ended in late August. All treatments were drip-irrigated (one dripper per plant, inserted in the propagation cube) with a complete nutrient solution adapted to plant development. The first 8.5 weeks after sowing, nutrient concentrations were as follows (in $\mathrm{mg} \cdot \mathrm{L}^{-1}$ ): 228 nitrogen $(\mathrm{N})\left(4 \% \mathrm{NH}_{4}^{+}\right), 63$ phosphorus, 337 potassium $(\mathrm{K}), 195$ calcium $(\mathrm{Ca}), 44$ magnesium, $163 \mathrm{SO}_{4}, 24$ chlorine $(\mathrm{Cl}), 1.52$ iron $(\mathrm{Fe}), 0.72$ manganese, 0.42 zinc, 0.08 copper, 1.13 boron, and 0.07 molybdenum. Thereafter, the following nutrient concentrations were changed to $201 \mathrm{~N}\left(4 \% \mathrm{NH}_{4}{ }^{+}\right)$, $353 \mathrm{~K}, 163 \mathrm{Ca}, 174 \mathrm{SO}_{4}$, and $1.56 \mathrm{Fe}$ for the next 9 weeks (that is 2 weeks after planting until fruit set from eight clusters) and finally to $171 \mathrm{~N}\left(5 \% \mathrm{NH}_{4}^{+}\right), 371 \mathrm{~K}, 179 \mathrm{SO}_{4}, 101 \mathrm{Cl}$, and $1.62 \mathrm{Fe}$ for the 14 remaining weeks of growth, corresponding to the fourth to 17 th week before harvest. During cultivation, the EC of the nutrient solution was set to $2.5 \mathrm{dS} \cdot \mathrm{m}^{-1}$, except in treatments with capillary rise, for which it was $2.0 \mathrm{dS} \cdot \mathrm{m}^{-1}$ to avoid accumulation of salts at the substrate upper surface. For all treatments, the $\mathrm{pH}$ of the nutrient solution was maintained at 5.7 to 5.8.

Leachate was collected and measured daily across the experimental unit (two containers or slabs per experimental unit) of two of the six blocks. Water use was calculated by taking into account average surface evaporation in the SP container, which was estimated to be $120 \mathrm{~mL}$ per container per $24 \mathrm{~h}$. This estimate was made using two plant-free containers filled with substrates, which were watered every day; the water content was measured by weighing the plant-free containers at regular intervals over 3 consecutive days during four different periods, referred to as periods 1 to 4 ( 5 to 7 May, 25 to 27 May, 13 to 15 June, and 5 to 7 July). The amount of nutrient solution applied was obtained from flow meter readings taken daily for all treatments and accuracy was carefully compared on seven different occasions using applied water measured on two sets of four different drippers. Dripper lines were also checked for uniformity on two occasions using new and used drippers.

\section{Greenhouse conditions and crop management}

The experiment was conducted in a Venlotype glasshouse (Harnois Industries, SaintThomas-de-Joliette, Quebec, Canada) at Laval
University (lat. $46^{\circ} 47^{\prime} \mathrm{N}$, long. $71^{\circ} 23^{\prime} \mathrm{W}$ ), Quebec, Canada. Seeds (Solanum lycopersicum cv. Trust) were sown into rockwool cells on $13 \mathrm{Jan}$. and then transplanted into rockwool cubes $(15 \mathrm{~cm} \times 10 \mathrm{~cm} \times 6.5 \mathrm{~cm})$. At 4.5 weeks, seedlings were planted into the SP growing media or rockwool at a density of four plants per container or slab. Both substrates were saturated with nutrient solution for $24 \mathrm{~h}$ and drained before planting to facilitate water retention. The initial substrate volume per plant was $3 \mathrm{~L}$ for RW/TM, 3.4 L for SP/TM and SP/TS-1.5, and 3.1 L for SP/C-1.1 and $\mathrm{SP} / \mathrm{C}-0.9$. The planting density was 2.9 plants $/ \mathrm{m}^{2}$. The plants were grown on north-southoriented slabs $75 \mathrm{~cm}$ above the ground.

The average temperature in the greenhouse (March to August) was $23{ }^{\circ} \mathrm{C}$ during the day $\left( \pm 7.5^{\circ} \mathrm{C}\right)$ and $19{ }^{\circ} \mathrm{C}\left( \pm 6{ }^{\circ} \mathrm{C}\right)$ at night. When solar radiation was lower than $450 \mathrm{~W} \cdot \mathrm{m}^{-2}$, supplemental lighting was provided by high vapor pressure sodium lamps $(400 \mathrm{~W}$; PL Light Systems Canada Inc., Ontario, Canada) for $16 \mathrm{~h}$ of photosynthetic photon flux density of $150 \mu \mathrm{mol} \cdot \mathrm{m}^{-2} \cdot \mathrm{s}^{-1}$. Supplemental lighting was turned off when solar radiation was higher than $650 \mathrm{~W} \cdot \mathrm{m}^{-2}$. No $\mathrm{CO}_{2}$ enrichment was provided. Pests were controlled by biological control methods, and bumblebees (Bombus impatiens) were used for pollination. Two applications of myclobutanil (Nova 40WP; Dow AgroSciences Canada, Inc.) were made to control mildew. Clusters were pruned at four fruits; fruits were harvested biweekly over 17 weeks (2 May to 24 Aug.) and classified according to size, shape, and presence of physiological disorders (Class 1: no visible defects, Class 4: unmarketable).

\section{Growing media composition and analysis}

The substrate (SP) was a mixture of two volumes of white spruce sawdust [Picea glauca (Moench) Voss.] sieved to less than $6 \mathrm{~mm}$ and one volume of brown sphagnum peat (H4-H5 on von Post). Composted manure (cattle, swine, and chicken; Les Composts du Québec Inc., Quebec, Canada) was incorporated to make up the final volume ( $8 \%$ of the sawdust:peat volume). In the manufacturing sequence, peat $\mathrm{pH}$ was adjusted to 5.5 using horticultural-grade calcitic limestone (4.6 g. $\mathrm{L}^{-1}$ of peat), which was incorporated by mixing with peat for $5 \mathrm{~min}$ in a rotating barrel.

Sawdust and compost were then added and mixed for $15 \mathrm{~min}$. Particle-size distribution of the mix and its components was measured after $1 \mathrm{~min}$ of hand sieving (Table 1). Two types of plastic containers were used: commercial plastic rectangular containers $(41.5 \mathrm{~cm}$ long $\times 28 \mathrm{~cm}$ wide $\times 13 \mathrm{~cm}$ high) $($ Fig. $1 \mathrm{~A})$ for variable irrigation and a prototype rectangular container $(40.5 \mathrm{~cm}$ long $\times 30 \mathrm{~cm}$ wide $\times 13 \mathrm{~cm}$ high) with a bottom-located water reservoir designed to store leachate and maintain a constant water potential and adequate aeration (Fig. 1C-D). A geotextile at the bottom of the upper tray allowed the rise of water by capillarity from the reservoir to the substrate and a perforated plate located below the geotextile allowed air circulation (Fig. 1B).
Table 1. Particle-size distribution of sawdust, peat, and the sawdust-peat-compost mix.

\begin{tabular}{lcrr}
\hline & \multicolumn{3}{c}{$\begin{array}{c}\text { Particle-size distribution } \\
(\% \text { wt })\end{array}$} \\
\cline { 2 - 4 } & Sawdust & Peat & Mix \\
\hline $16-25 \mathrm{~mm}$ & 0.0 & 1.9 & 0.1 \\
$8-16 \mathrm{~mm}$ & 0.1 & 7.0 & 2.8 \\
$4-8 \mathrm{~mm}$ & 8.3 & 11.6 & 7.5 \\
$2-4 \mathrm{~mm}$ & 35.8 & 12.4 & 23.8 \\
$1-2 \mathrm{~mm}$ & 27.1 & 19.6 & 25.6 \\
$0.5-1 \mathrm{~mm}$ & 22.1 & 30.5 & 21.4 \\
$0.25-0.5 \mathrm{~mm}$ & 5.1 & 10.0 & 8.7 \\
Less than 0.25 mm & 1.3 & 3.2 & 9.4 \\
Losses & 0.2 & 3.6 & 0.6 \\
\hline
\end{tabular}

A root barrier above the geotextile prevented roots from invading this material. Both containers had four drainage holes, which were located in the lower corners of the commercial containers and in the bottom at both ends in the prototype (Fig. 1E). The height of those holes, and therefore the height of water in the reservoir, allowed control of substrate water potential in the container after drainage. Two matric potentials were applied by controlling this height: -0.9 and $-1.1 \mathrm{kPa}$ at the midsubstrate height. Master Dry Rockwool slabs (Agro Dynamics, Ontario, Canada) measuring $50 \mathrm{~cm}$ long $\times 24 \mathrm{~cm}$ wide $\times$ $10 \mathrm{~cm}$ high were used as a control substrate.

Water retention curves (relationship between matric potential and water content) were determined from measurements of water content using time domain reflectometry (TDR) readings taken at midheight $(5 \mathrm{~cm}$ for the slabs and $6 \mathrm{~cm}$ for substrate) on samples placed on a tension table (Paquet et al., 1993). For the SP substrate, dielectric constant readings $(\mathrm{Ka})$ obtained by TDR were converted to volumetric water content $(\theta)$ using the equation developed by Paquet et al. (1993) for Ka less than 55:

$$
\begin{aligned}
\theta= & -0.0055+0.0425 \mathrm{Ka} \\
& -0.000975 \mathrm{Ka}^{2}+0.00000907 \mathrm{Ka}^{3}
\end{aligned}
$$

For $\mathrm{Ka}=55$ or greater in SP, the equation used to convert Ka to $\theta$ was obtained from the interpolation line drawn from the predicted $\theta$ at $\mathrm{Ka}=55$ (Caron et al., 2002a) to a Ka value of 80 with $\theta$ theoretically equal to $1 \mathrm{~cm}^{3} \cdot \mathrm{cm}^{-3}$.

$$
\theta=0.0042 \mathrm{Ka}+0.6635
$$

For rockwool, the Caron et al. (2002a) equation was used for Ka less than 72.5:

$$
\theta=0.1357 \mathrm{Ka}^{0.5}-0.1672
$$

Finally, for $\mathrm{Ka}=72.5$ or greater in rockwool, the equation used to convert $\mathrm{Ka}$ to $\theta$ was obtained from the interpolation line drawn from the predicted $\theta$ at $\mathrm{Ka}=72.5$ (Caron et al., 2002a) to a Ka value of 80 with $\theta$ theoretically equal to $1 \mathrm{~cm}^{3} \cdot \mathrm{cm}^{-3}$, which then yields:

$$
\theta=0.0725 \mathrm{Ka}^{0.5}+0.3512
$$

Air-filled porosities were calculated using total porosity obtained from the water 
desorption curves and the volumetric water content during the experiments with measurement at the same intervals as before (Periods 1 to 4 ).

\section{Measurements and analyses}

The five treatments were arranged in a randomized complete block design with six replicates (eight plants per experimental unit). Throughout the growing season, three of the six blocks were instrumented with homemade pressure transducer tensiometers (Model PX26; Omega Instruments, Montreal, Quebec, Canada) to monitor matric potential at midsubstrate height $(6.5 \mathrm{~cm}$ for containers and $5 \mathrm{~cm}$ for rockwool slabs) at 2-min intervals in each treatment.

Gas samples were collected using a syringe sampler (Juneau et al., 2006) placed permanently at midsubstrate height $(6.5 \mathrm{~cm}$ height for both container types and $5 \mathrm{~cm}$ height for the rockwool slab) (Fig. 1E). For treatments with capillary rise, a second gas sample was collected using a sampler placed in the bottom of the pan $1 \mathrm{~cm}$ under the perforated plate. Samples were analyzed by gas chromatography (Rochette et al., 2004) to determine soil air concentrations of oxygen $\left(\mathrm{O}_{2}\right)$, carbon dioxide $\left(\mathrm{CO}_{2}\right)$, and nitrous oxide $\left(\mathrm{N}_{2} \mathrm{O}\right)$. Nutrient solution samples of the SP growing media were taken at $6 \mathrm{~cm}$ height using $10-\mathrm{cm}$-long lysimeters with a $0.3-\mathrm{cm}$ radius $\times 2.5-\mathrm{cm}-$ long porous cup (Model 0652X03-B01M3; Soil Moisture Equipment, Santa Barbara, CA) exerting a suction of $-5 \mathrm{kPa}$, whereas a $50-\mathrm{mL}$ syringe was used for the rockwool slabs. The EC and $\mathrm{pH}$ of these samples were then measured with a conductivity meter (Accumet probe Model 1362015 mounted on a Yellow Springs Instrument Model YSI 35, Yellow Springs, OH) and a $\mathrm{pH}$ meter (Symphony SB70C model; VWR, Mont-Royal, Quebec, Canada). Sampling and analysis were performed on the same three replicates of all five treatments using permanently installed lysimeters or syringes four different times at 3-week intervals. The substrate water content was measured by TDR (Tektronix 1502C; Topp et al., $1980)$ using one vertically (12-cm long) and three (12-cm long) horizontally installed rod probes $(3,6$, and $9 \mathrm{~cm}$ deep) for the container treatments and rods installed $2.5,5$, and $7.5 \mathrm{~cm}$ deep for the rockwool slabs, at four different times, at 3-week intervals.

At the end of the experiment, three containers per treatment from three different blocks were split into two equal parts. Subsamples of $150 \mathrm{~cm}^{3}$ were collected from half of the substrate at each of four different depths $(1.5 \mathrm{~cm}, 4.5 \mathrm{~cm}, 7.5 \mathrm{~cm}$, and $10.5 \mathrm{~cm})$; the samples were taken between the plant rooting cubes and the center of the containers. The EC was measured on saturated medium extract (SME) obtained from these subsamples by following the SME protocol (Conseil des Productions Végétales du Québec, 1988). In the other half, a cylindrical form was cut with a knife to fit into a cylinder $15 \mathrm{~cm}$ diameter and $18 \mathrm{~cm}$ high, and the water retention curve of three experimental blocks per treatment was measured according to the method of Caron et al. (2008). The substrate was brought to saturation by gradually increasing the water level $1.5 \mathrm{~cm}$ per hour and maintained at saturation for $24 \mathrm{~h}$. Container capacity was obtained after $2 \mathrm{~h}$ of free drainage. The water content values at saturation and container capacity were measured using handmade 12-cm-long stainless steel rod TDR probes inserted vertically (Topp et al., 1980). The water content was also measured with horizontally inserted TDR probes (at midsubstrate height) after equilibration of samples at different water potential levels on a tension table (Topp and Zebchuk, 1979).

\section{Statistical analysis}

Data were analyzed by analysis of variance and a priori contrasts were constructed with SAS/STAT Version 9.2 (SAS Institute, Inc., 2008). The analysis was carried out as a split-plot-in-time with treatments within blocks as main plots and subplots in time or for each specific time separately as a complete block design in the presence of a significant time $\times$ treatment interaction. Monthly means of weekly collected data were used for statistical analyses.

\section{Results and Discussion}

\section{Expt. 1: Irrigation trigger set points for optimal plant activity}

For rockwool, the maximum photosynthetic rate as a function of substrate water potential was observed at a point close to saturation with the highest photosynthetic rate recorded when water potential tended toward container capacity for rockwool $(-0.5 \mathrm{kPa})$, reaching a plateau from $-0.2 \mathrm{kPa}$ to $-1.2 \mathrm{kPa}$ (Fig. 2A). Photosynthesis was measurable at water potential levels from $-0.2 \mathrm{kPa}$ down to the wilting point in rockwool. This is consistent with theoretical predictions because
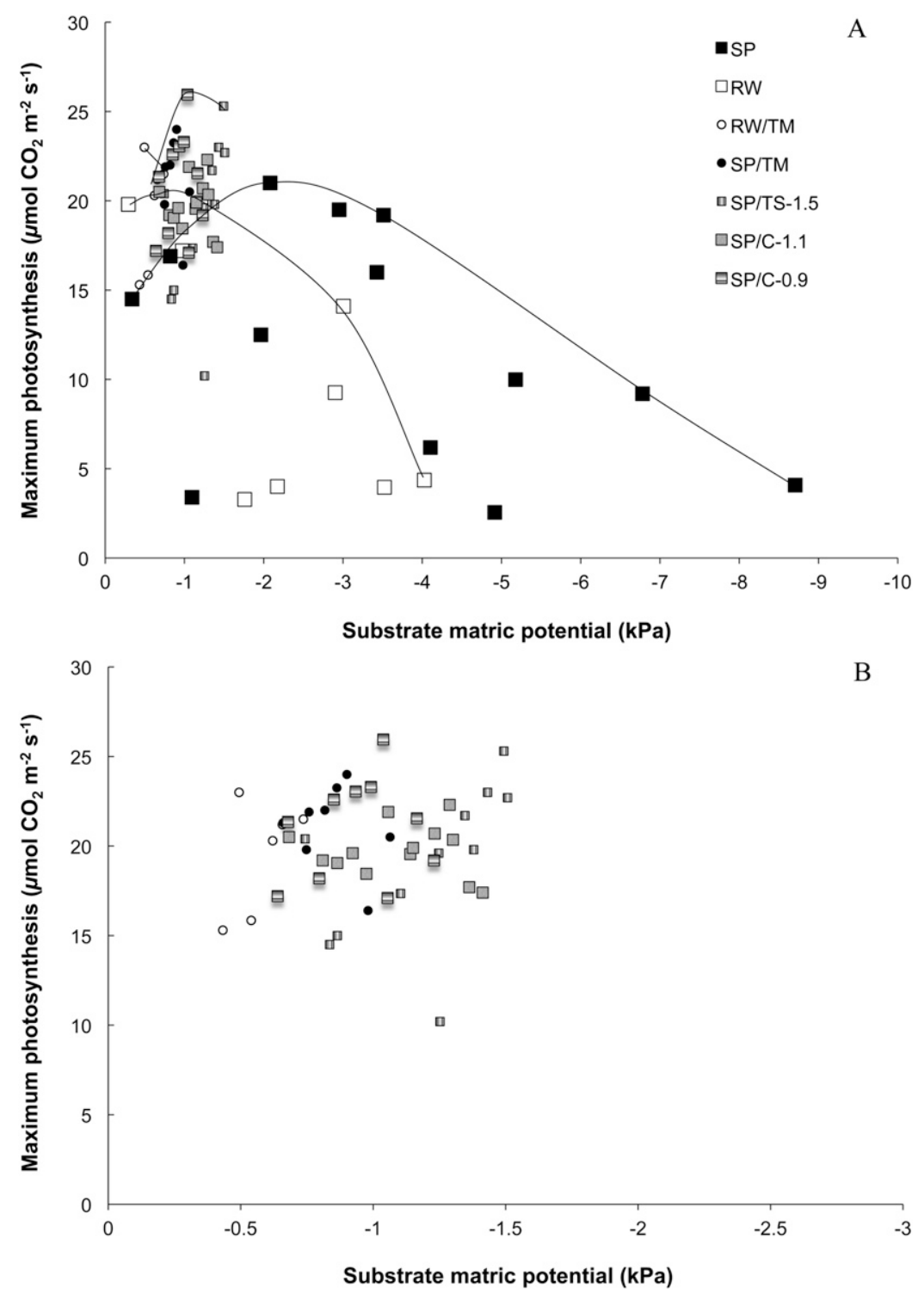

Fig. 2. (A-B) Maximum photosynthetic rate as a function of substrate matric potential for rockwool (RW) and sawdust-peat mixtures (SP) used in Expt.1 and in Expt. 2 (A) with a detailed view of Expt. 2 data. Boundary lines were drawn along maximum values (Webb, 1972). 
when substrates are saturated and drained, they will equilibrate at soil water potential corresponding to free water sitting at the bottom of the substrate. Hence, for a $10-\mathrm{cm}$ high substrate like rockwool, when a full probe is inserted to a $5-\mathrm{cm}$ depth, the reading should be $-0.5 \mathrm{kPa}$. Therefore, the readings obtained at $-0.5 \mathrm{kPa}$ corresponded to substrate conditions at container capacity for rockwool. Hence, water potential values that were $\approx-0.2 \mathrm{kPa}$ corresponded to measurements that were taken during irrigation events, because soil water potential is then observed to reach values higher than container capacity. A very sharp decrease in the photosynthetic rate was observed when water potential fell below $-1.2 \mathrm{kPa}$; this is likely attributable to the water desorption curve of this dry type of rockwool, which shows a fast drop in water content as soon as water potential decreases (Fig. 3A). For the SP substrate, maximum photosynthesis was observed at a lower substrate water potential than for rockwool $(\approx 2.2 \mathrm{kPa})$, which can be explained by the less pronounced drop in water content that occurs with decreasing water potential for peat-sawdust (Fig. 3). In contrast to the rockwool growing media, a pronounced drop in the photosynthetic rate of SP-grown plants was also observed at a point close to container capacity $(\approx 0.6 \mathrm{kPa})$. This effect may be linked to a lack of oxygen, because organic-based substrates have higher respiratory needs than rockwool (Desbiens, 2004; Naasz et al., 2009). Meanwhile, the maximum photosynthetic rate for the SP substrate may reach slightly higher values than for rockwool when irrigation management is well controlled (Fig. 2). Indeed, statistical tests performed on the regression lines drawn by the boundary line approach (Webb, 1972) showed significant linear and quadratic behavior and curves that differed between treatments, as indicated by the significant $\mathrm{WP} \times \mathrm{WP} \times$ substrate interaction. Significant substrate effects were also observed (Table 2). A similar trend was observed for $g_{\mathrm{S}}$, with values being higher for SP at all substrate water potentials than for rockwool (data not shown). These response curves (Fig. 2) suggest that irrigation set points for the SP substrate were at a lower water potential than for rockwool. SP drying may favor a higher photosynthetic rate, because signs of anoxia were present at a point close to container capacity (equilibrium water content and potential after substrate saturation and drainage). Consequently, an excessively high water potential over a long time period may compromise the yield performance of the tomato crop in this substrate. In contrast, maximum photosynthesis and yield are obtained for rockwool-grown plants when the water potential reaches a level close to slab capacity, suggesting optimal aeration properties for the rockwool growing media at slab capacity.

\section{Expt. 2: Irrigation management based on starting or constant thresholds}

Photosynthesis measurements. When the activity of plants grown under four irrigation treatments was compared with plant activity for the rockwool control (Expt. 2), higher photosynthetic rates were observed for the SP treatments. The maximum photosynthetic rate was obtained at substrate matric potential values $\approx-1 \mathrm{kPa}$, which is higher than the optimal water potential values observed in Expt. 1 (Fig. 2A). Similar to Expt. 1, substrate had an effect and there was a significant quadratic component that differed between treatments (Table 2). When the treatments are compared, SP irrigation treatments based on water potential thresholds did not affect the photosynthetic rate compared with timer control irrigation treatment (Table 3). Indeed, when photosynthetic rates were averaged over their respective water potential values, no significant treatment effects were found, and there was no significant treatment $\times$ date interaction. By analysis of contrasts, significant differences were found for stem dry mass and yield for SP/TS-1.5 and rockwool, indicating that with appropriate management, sawdust has the potential to produce more shoot biomass and higher yield than the drytype rockwool with intermittent irrigation.

Relative to the curve obtained in Expt. 1 for the same SP and rockwool substrates, photosynthetic rates at lower matric potentials were increased in Expt. 2. In the SP treatments, the higher photosynthetic activity measured in Expt. 2 compared with Expt. 1 for the SP mix irrigated at high matric potentials greater than $-2 \mathrm{kPa}$ may be partly because the measurements in Expt. 2 were taken from May to July, a period when high irradiance

Table 2 . Probability value of the quadratic regression equation relating maximum photosynthesis to average substrate water potential (WP) at the commercial site (Expt. 1) and in the experimental setup (Expt. 2).

\begin{tabular}{lll}
\hline Effect & Expt. 1 & Expt. 2 \\
\hline Substrate & 0.0369 & 0.0184 \\
Water potential $(\mathrm{WP})$ & 0.0132 & 0.0261 \\
$\mathrm{WP} \times \mathrm{WP}$ & 0.0005 & 0.0241 \\
$\mathrm{WP} \times \mathrm{WP} \times$ substrates & 0.0005 & 0.0180 \\
Mean square error & 2.76 & 0.55 \\
\hline
\end{tabular}

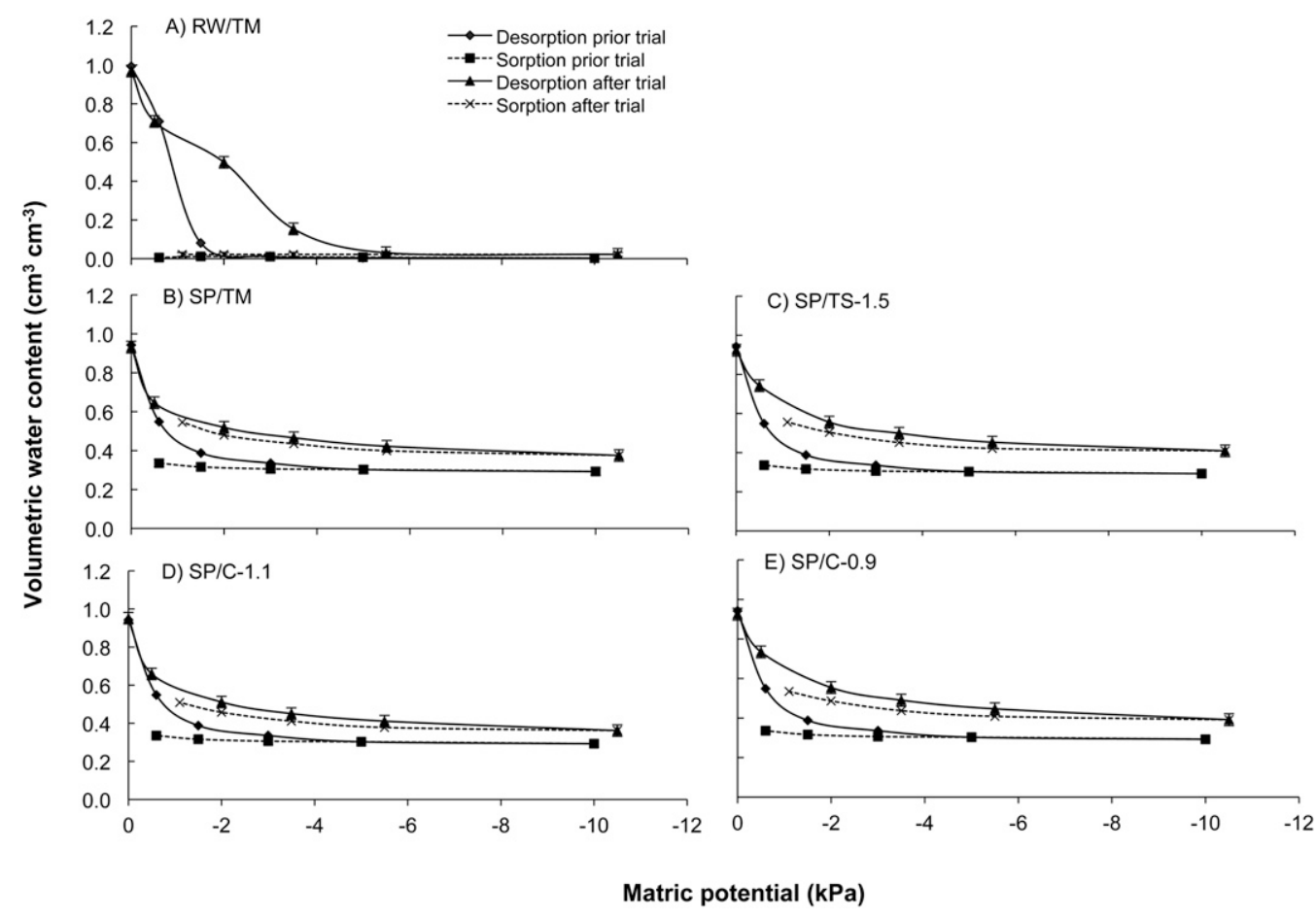

Fig. 3. Water desorption and sorption curve for the different substrates before use and at the end of Expt. 2. Errors bars were very low on rewetting. 
levels occurred, whereas the measurements in Expt. 1 were taken all year-round. Moreover, younger plants, which are more likely to have higher photosynthesis rates, were used in Expt. 2 relative to Expt. 1. An age effect may have occurred like that previously reported by Ayari et al. (2000) for tomato plants. Substrate compaction may also have played a role because the growing media in Expt. 2 were less than 3 months old compared with those in Expt. 1 (up to 12 months), and younger substrates showed higher air-filled porosity values than older ones (see Fig. 3 and section on water desorption curves), which were less susceptible to oxygen deficiency at values greater than $-2.0 \mathrm{kPa}$. In addition, the type of container used in Expt. 2 compared with Expt. 1 may have improved substrate aeration and plant activity, as discussed subsequently.

Water desorption curves and water content. Were the main differences in plant activity response to water potential in Expts. 1 and 2 resulting from substrate properties or to irrigation management? To properly characterize the relationship between substrate water content and substrate water potential, water desorption curves were obtained before use and at the end of Expt. 2 for both drainage and rewetting conditions (Fig. 3). These

Table 3. Average (four different times) photosynthesis, final biomass, and yield (17 weeks) of the different treatments.

\begin{tabular}{lccccc}
\hline Treatment & $\begin{array}{c}\text { Photosynthesis } \\
\left(\mu \mathrm{mol} \mathrm{CO}_{2} / \mathrm{m}^{2} / \mathrm{s}\right)\end{array}$ & $\begin{array}{c}\text { Root mass } \\
(\mathrm{g} / \mathrm{plant})\end{array}$ & $\begin{array}{c}\text { Stem dry mass } \\
(\mathrm{kg} / \mathrm{plant})\end{array}$ & $\begin{array}{c}\text { Leaf dry mass } \\
(\mathrm{kg} / \mathrm{plant})\end{array}$ & $\begin{array}{c}\text { Total marketable } \\
\text { yield }(\mathrm{kg} / \mathrm{plant})\end{array}$ \\
\hline $\mathrm{RW} / \mathrm{TM}$ & $20.2 \mathrm{a}^{z}$ & $16.7 \mathrm{a}$ & $0.071 \mathrm{c}$ & $0.050 \mathrm{ab}$ & $10.28 \mathrm{~b}$ \\
$\mathrm{SP} / \mathrm{TM}$ & $21.1 \mathrm{a}$ & $14.8 \mathrm{ab}$ & $0.073 \mathrm{c}$ & $0.051 \mathrm{ab}$ & $11.07 \mathrm{a}$ \\
$\mathrm{SP} / \mathrm{TS}-1.5$ & $20.9 \mathrm{a}$ & $12.4 \mathrm{~b}$ & $0.080 \mathrm{a}$ & $0.057 \mathrm{a}$ & $11.34 \mathrm{a}$ \\
$\mathrm{SP} / \mathrm{C}-1.1$ & $20.1 \mathrm{a}$ & $15.0 \mathrm{a}$ & $0.079 \mathrm{ab}$ & $0.054 \mathrm{ab}$ & $11.00 \mathrm{a}$ \\
$\mathrm{SP} / \mathrm{C}-0.9$ & $22.4 \mathrm{a}$ & $15.1 \mathrm{a}$ & $0.074 \mathrm{bc}$ & $0.049 \mathrm{~b}$ & $10.81 \mathrm{a}$ \\
$P$ value & 0.28 & 0.04 & 0.01 & 0.19 & 0.16 \\
LSD & 3.2 & 2.5 & 0.005 & 0.007 & 1.00 \\
Contrasts & & & & & 0.07 \\
$\quad$ RW/TM - SP/TS-1.5 & 0.90 & 0.01 & 0.01 & 0.07 & 0.53 \\
SP/TM - SP/TS-1.5 & 0.51 & 0.06 & 0.01 & 0.11 & 0.43 \\
SP/TS-1.5 - SP/C-1.1 & 0.53 & 0.04 & 0.64 & 0.32 & 0.65 \\
SP/C-1.1 - SP/C-0.9 & 0.30 & 0.95 & 0.07 & 0.2 & \\
\hline
\end{tabular}

${ }^{\mathrm{z}}$ Means with the same letter do not differ significantly at $P=0.05$ using protected LSD test. $\mathrm{RW}=$ rockwool; $\mathrm{TM}=$ timer-based irrigation; $\mathrm{SP}=$ sawdust-peat; $\mathrm{TS}=$ tensiometer-based irrigation; $\mathrm{C}=$ constant water potential; LSD = least significant difference. curves showed a very sharp decrease in water content with decreasing water potential from 0 to $-2 \mathrm{kPa}$, and this effect was significantly $(P=0.01)$ more pronounced for rockwool (before use) substrate than for SP treatments (Fig. 3). This result is attributable to the dry type of rockwool used (see Appendix). Also, the very coarse particle-size distribution explains the sharp decrease for SP (Table 1) compared with the slow decrease generally observed for peat-based growing media (Paquet et al., 1993). The drop in water content was very steep for the unused rockwool substrate; the substrate lost nearly all its water at a potential higher than $-2.0 \mathrm{kPa}$ (Fig. 3). At $-2.0 \mathrm{kPa}$, the unused rockwool substrate lost nearly all its water content, whereas the water content of unused SP substrates continued to drop until $-5 \mathrm{kPa}$, although their decreasing slope was much lower between -0.05 and $-5.0 \mathrm{kPa}$. This marked difference between the two substrates was well correlated with the observed decline of photosynthesis under decreasing water potential for rockwool.

As expected from the water desorption curve, substrate water content at all depths during the period May to July showed significantly higher water content for SP compared with the rockwool substrate (Fig. 4). The constant height device SP/C-0.9 was the wettest and the constant height device SP/C1.1 the driest of the SP treatments, whereas the other treatments had intermediate values,
A) $3 \mathrm{~cm}$

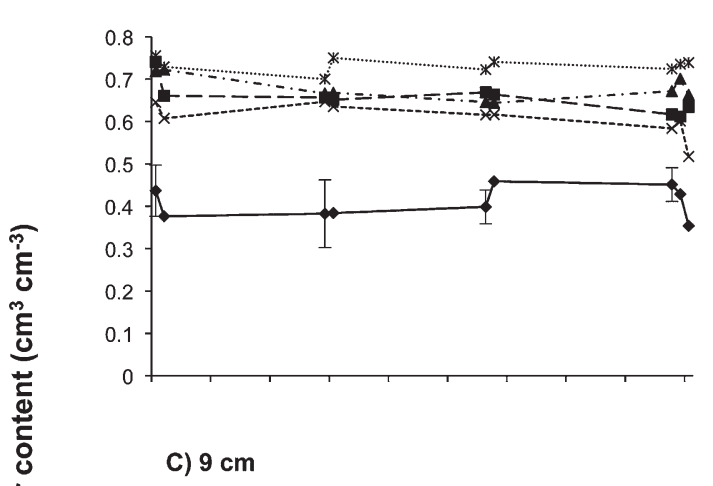

B) $6 \mathrm{~cm}$

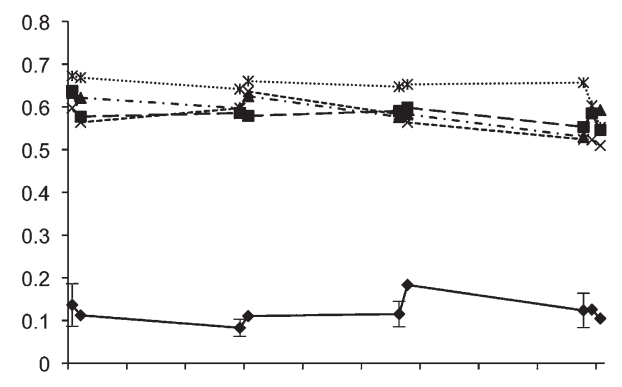

D) Whole depth

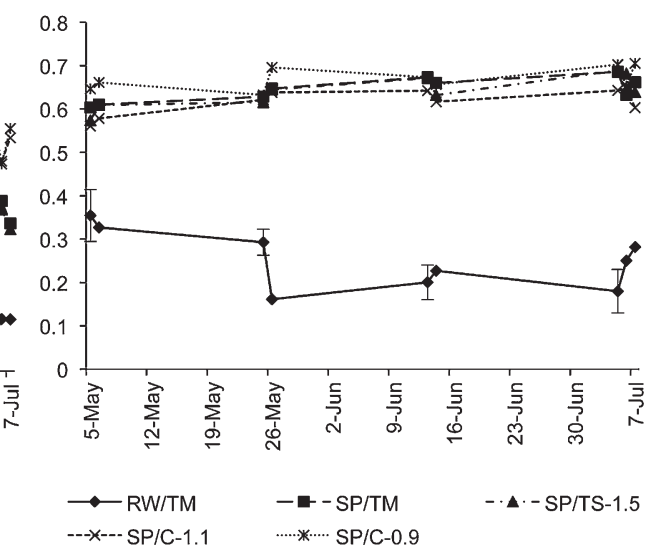

Fig. 4. Measured water content at different heights in centimeters (horizontal probes) and for the whole depth (vertical probes) on nine different days (averaged value obtained between 1100 and $1530 \mathrm{HR}$ ). The vertical bars represent the least significant difference for treatment comparisons on each individual date. 
being very close to saturation at $3 \mathrm{~cm}$ from the bottom $\left(0.70\right.$ to $\left.0.76 \mathrm{~cm}^{3} \cdot \mathrm{cm}^{-3}\right)$ and ranging from 0.48 to $0.76 \mathrm{~cm}^{3} \cdot \mathrm{cm}^{-3}$ at all depths and times. All systems had relatively constant water content during all measurement periods, with a variance of 0.05 to 0.07 for the SP treatments and 0.10 for rockwool for the average vertical readings (Table 4). Indeed, the data showed a significant but very small time effect, which was 200 times smaller than the treatment effects.

\section{Oxygen content and aeration structure}

Expected air-filled porosity (AFP) values were estimated from the water desorption curve and the water content, and AFP values between 0.20 and $0.32 \mathrm{~cm}^{3} \cdot \mathrm{cm}^{-3}$ were observed at the $3-\mathrm{cm}$ height in all treatments, except for rockwool (Table 4), in which it reached $0.54 \mathrm{~cm}^{3} \cdot \mathrm{cm}^{-3}$. These AFP values for SP may create aeration limitations at the bottom of the pot, particularly when respiratory activities are high (Naasz et al., 2009) and when the oxygen content in the reservoir is lower than atmospheric level, as reported subsequently. This may explain the lower plant activity close to saturation in the sawdust-peat mix relative to rockwool.

However, the prototype container, which is designed to compensate for low aeration and hence low gas diffusion, should limit the negative effect of low AFP values and maintain high oxygen values. Rockwool, on the other hand, should not develop aeration limitations because of the lower water content present at all depths and therefore its higher AFP and also because of the gas exchange that may occur along the periphery of the slab (Allaire et al., 2005). Figure 5 shows that oxygen contents were significantly lower for all treatments except rockwool at the beginning and then gradually reached the same level as rockwool later on (no significant treatment effect on the last sampling date). Therefore, aeration limitations still occurred despite the modified container design. This is consistent with the lower AFP characterizing SP substrates and may also be related to significant microbial activity that occurs in the early crop resulting from the readily

Table 4. Average water content and variance estimates (vertical TDR measurements) along with air-filled porosity estimated at $3 \mathrm{~cm}$ depth.

\begin{tabular}{lcccc}
\hline Treatment (units) & No. & Means $\left(\mathrm{cm}^{3} \cdot \mathrm{cm}^{-3}\right)$ & Variance $\left(\mathrm{cm}^{6} \cdot \mathrm{cm}^{-6}\right)$ & $\begin{array}{c}\text { Air-filled porosity at } 3 \mathrm{~cm} \\
\text { depth }\left(\mathrm{cm}^{3} \cdot \mathrm{cm}^{-3}\right)\end{array}$ \\
\hline RW/TM & 48 & $0.260 \mathrm{c}^{2}$ & 0.100 & $0.54 \mathrm{a}$ \\
SP/TM & 48 & $0.630 \mathrm{ab}$ & 0.068 & $0.26 \mathrm{c}$ \\
SP/TS-1.5 & 48 & $0.637 \mathrm{ab}$ & 0.056 & $0.24 \mathrm{~cd}$ \\
SP/C-1.1 & 48 & $0.618 \mathrm{~b}$ & 0.049 & $0.32 \mathrm{~b}$ \\
SP/C-0.9 & 48 & $0.650 \mathrm{a}$ & 0.075 & $0.20 \mathrm{~d}$ \\
LSD & & 0.026 & & 0.056 \\
\hline
\end{tabular}

${ }^{\mathrm{z}}$ Means with the same letter do not differ significantly at $P=0.05$ using protected LSD test.

$\mathrm{RW}=$ rockwool; $\mathrm{TM}=$ timer-based irrigation; $\mathrm{SP}=$ sawdust-peat; $\mathrm{TS}=$ tensiometer-based irrigation; $\mathrm{C}=$ constant water potential. available organic components in these substrates as has been reported for bark (Naasz et al., 2009). Despite these lower oxygen levels, the level in SP remained higher than $17 \%$, reducing the risk of oxygen limitation. Surprisingly, the presence of an aeration structure did not increase oxygen to levels higher than those found in tensiometer or timer-irrigated sawdust, possibly because convective fluxes induced by wetting and drying may have caused significant oxygen movement within the substrate, whereas convective fluxes were more limited in a capillary rise constant matric potential device. Hence, the design of the container was not optimal and requires further modifications.

The $\mathrm{CO}_{2}$ concentrations were higher within the substrates than in the air or in the reservoir. Like in raw sawdust, high microbial respiration (Desbiens, 2004) is expected and a relatively slow gas diffusion process dominates in wet substrates. As a result, increases in $\mathrm{CO}_{2}$ levels are likely to be observed. Denitrification of nitrate fertilizer and ethylene production are favored at high water potential and in the presence of labile carbon (Webster and Goulding, 1989) and accumulation occurs because of the relatively slow diffusion, as observed (Fig. 5). Lower plant activity at potentials higher than $-1.0 \mathrm{kPa}$ may be the result of ethylene accumulation, which is observed at high water content and low oxygen level (Smith and Dowdell, 1974). This is supported by the fact that in the two $\mathrm{SP} / \mathrm{C}$ treatments, the wettest one (SP/C-0.9) showed higher $\mathrm{CO}_{2}$ and $\mathrm{N}_{2} \mathrm{O}$ levels within the substrate relative to the $\mathrm{SP} / \mathrm{C}-1.1$ treatment, which was drier and had significantly higher AFP.
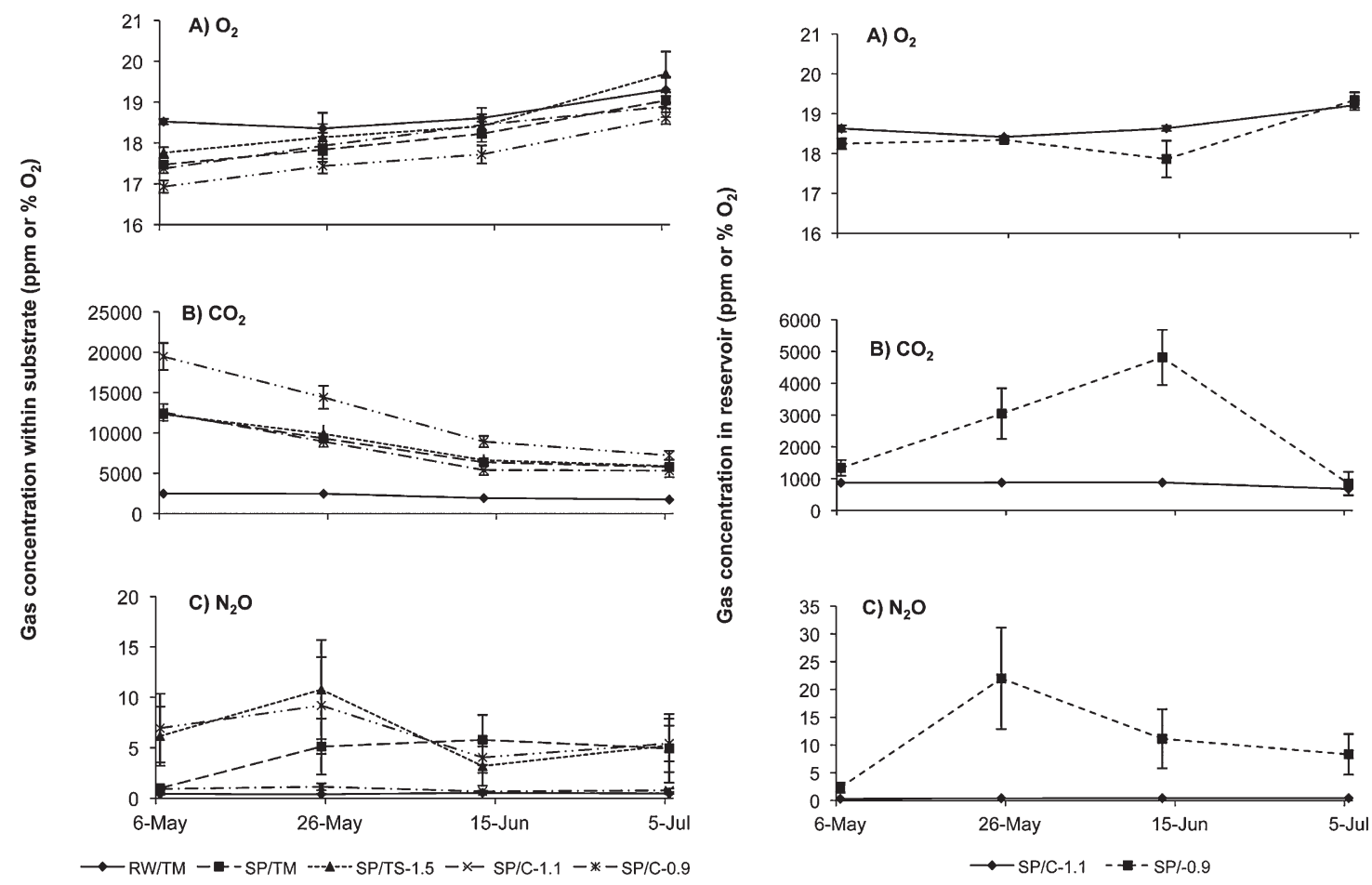

Fig. 5. Oxygen (A) carbon dioxide (B), and nitrous oxide concentrations $(\mathbf{C})$ and in the bottom reservoir for all four measurements. Treatment effects were significant on all dates except 5 and 6 July for oxygen. In the bottom reservoir treatment, effects were significant in Periods 2 and 3 only. 
Table 5. Average EC and average $\mathrm{pH}$ of leachate water.

\begin{tabular}{|c|c|c|c|c|c|c|c|c|c|c|c|c|}
\hline \multirow[b]{2}{*}{ Treatments } & \multicolumn{6}{|c|}{$\mathrm{EC}\left(\mathrm{dS} \cdot \mathrm{m}^{-1}\right)$} & \multicolumn{6}{|c|}{$\mathrm{pH}$} \\
\hline & March & April & May & June & July & August & March & April & May & June & July & August \\
\hline$\overline{\mathrm{RW}} / \mathrm{TM}$ & 4.70 & 5.09 & 4.97 & 4.47 & 3.82 & 3.78 & 6.3 & 5.7 & 5.6 & 5.7 & 5.8 & 6.2 \\
\hline SP/TM & 3.92 & 4.58 & 4.76 & 4.03 & 3.89 & 3.76 & 6.3 & 6.2 & 6.2 & 6.0 & 5.9 & 6.0 \\
\hline SP/TS-1.5 & 4.47 & 4.29 & 4.69 & 5.12 & 4.64 & 4.24 & 6.3 & 6.1 & 6.1 & 5.9 & 5.8 & 6.1 \\
\hline $\mathrm{SP} / \mathrm{C}-1.1$ & 3.57 & 4.36 & 3.89 & 3.81 & 3.88 & 4.13 & 6.3 & 6.1 & 6.2 & 6.1 & 6.1 & 6.4 \\
\hline $\mathrm{SP} / \mathrm{C}-0.9$ & 3.95 & 4.54 & 3.14 & 4.05 & 6.86 & 4.99 & 6.5 & 6.3 & 6.7 & 6.7 & 6.3 & 6.6 \\
\hline$P$ value & 0.091 & 0.584 & 0.136 & 0.450 & 0.288 & 0.413 & 0.548 & 0.002 & 0.001 & 0.002 & 0.035 & 0.048 \\
\hline \multicolumn{13}{|l|}{ Contrasts } \\
\hline RW/TM - SP/TS-1.5 & 0.491 & 0.184 & 0.655 & 0.396 & 0.579 & 0.503 & 0.930 & 0.001 & 0.002 & 0.109 & 0.478 & 0.414 \\
\hline SP/TM - SP/TS-1.5 & 0.148 & 0.604 & 0.904 & 0.187 & 0.608 & 0.485 & 0.880 & 0.265 & 0.502 & 0.244 & 0.415 & 0.508 \\
\hline $\mathrm{SP} / \mathrm{TS}-1.5-\mathrm{SP} / \mathrm{C}-1.1$ & 0.044 & 0.902 & 0.247 & 0.129 & 0.603 & 0.870 & 0.800 & 0.391 & 0.929 & 0.134 & 0.037 & 0.062 \\
\hline $\mathrm{SP} / \mathrm{C}-1.1-\mathrm{SP} / \mathrm{C}-0.9$ & 0.283 & 0.740 & 0.278 & 0.745 & 0.093 & 0.244 & 0.184 & 0.025 & 0.002 & 0.002 & 0.153 & 0.337 \\
\hline
\end{tabular}

Table 6. EC of the nutrient solution at the rhizosphere level for samples obtained with suction cup samplers inserted into the substrates.

\begin{tabular}{lcccc}
\hline & \multicolumn{4}{c}{ EC $\left(\mathrm{dS} \cdot \mathrm{m}^{-1}\right)$} \\
\cline { 2 - 5 } Treatments & 5 to $6 \mathrm{May}$ & 25 to 26 May & 13 to 14 June & 5 to 6 July \\
\hline RW/TM & $3.58 \mathrm{~b}^{\mathrm{y}}$ & $4.03 \mathrm{a}$ & $2.88 \mathrm{~d}$ & $2.87 \mathrm{a}$ \\
SP/TM & $6.85 \mathrm{a}$ & $6.34 \mathrm{a}$ & $5.34 \mathrm{ab}$ & $4.82 \mathrm{a}$ \\
SP/TS-1.5 & $4.47 \mathrm{~b}$ & $5.70 \mathrm{a}$ & $6.09 \mathrm{a}$ & $6.65 \mathrm{a}$ \\
SP/C-1.1 & $3.40 \mathrm{~b}$ & $4.90 \mathrm{a}$ & $4.66 \mathrm{bc}$ & $8.69 \mathrm{a}$ \\
SP/C-0.9 & $4.08 \mathrm{~b}$ & $4.35 \mathrm{a}$ & $3.07 \mathrm{~cd}$ & $6.25 \mathrm{a}$ \\
$P$ value & 0.003 & 0.086 & 0.003 & 0.266 \\
LSD $(0.05)$ & 1.63 & 1.98 & 1.41 & 6.29 \\
& & & & 0.096 \\
Contrast & & & & 0.001 \\
$\quad$ RW/TM - SP/TM & 0.254 & 0.076 & 0.317 & 0.516 \\
SP/TM - SP/TS-1.5 & 0.008 & 0.495 & 0.074 & 0.441 \\
SP/TS-1.5- SP/C-1.1 & 0.176 & 0.418 & 0.051 & \\
SP/C-1.1 - SP/C-0.9 & 0.379 & 0.498 & & \\
\hline
\end{tabular}

${ }^{\mathrm{z} C o n t r a s t s ~ b e t w e e n ~ d i f f e r e n t ~ t r e a t m e n t s ~ f o r ~ t h e ~ s a m e ~ s a m p l i n g ~ p e r i o d . ~}$

${ }^{\mathrm{y}}$ Means with the same letter do not differ significantly at $P=0.05$ using protected LSD test.

$\mathrm{EC}=$ electrical conductivity; RW = rockwool; $\mathrm{TM}=$ timer-based irrigation; $\mathrm{SP}=$ sawdust-peat; TS = tensiometer-based irrigation; $\mathrm{C}=$ constant water potential; $\mathrm{LSD}=$ least significant difference.

The oxygen content at the bottom of the reservoir was found to be lower than the atmospheric level, whereas the $\mathrm{CO}_{2}$ concentration was higher (Fig. 5). This may be explained by restricted diffusion from the exterior air to the interior of the container and by root respiration at the mat-reservoir interface. Note that the container constant water potential device had significantly higher root dry mass than the SP/TS-1.5 treatment (Table 3). Because the reservoir was filled with leachates containing organic material (humic and fulvic acids and free sugars), denitrification and microbial respiration may have occurred as indicated by higher reservoir $\mathrm{N}_{2} \mathrm{O}$ and $\mathrm{CO}_{2}$ concentrations in 26 May and 15 June for the SP/C-0.9 (containing more solution in the reservoir) treatment relative to the drier SP/C-1.1 one. Consequently, oxygen or air enrichment in the bottom reservoir should be provided to improve the oxygen substrate concentration or to lower $\mathrm{CO}_{2}$ and $\mathrm{N}_{2} \mathrm{O}$ concentrations in the substrate, because the aeration structures present in this type of container were not sufficiently effective. Hence, the possibility of improving aeration or decreasing $\mathrm{CO}_{2}$ and ethylene concentration through the bottom of the substrate with this structure is limited if no additional air is provided to the bottom and, in practical terms, this implies that convective fluxes of exterior air into the reservoir should be provided if aeration is to be implemented from the bottom of this type of container. Therefore, improving the aeration within these reservoirs may be a way to further increase photosynthetic activity, shoot growth, and yield, but this approach deserves further investigation, particularly with respect to imposing convective fluxes or to a reservoir design that is more efficient at equilibrating the gas concentration with the atmospheric concentration, because previous oxygen enrichment studies showed positive effects on the growth and yield of greenhouse tomato plants (Dorais and Pepin, 2011).

\section{Electrical conductivity and water and nutrient use}

In general, the treatments studied did not have a significant effect on the $\mathrm{EC}$ or $\mathrm{pH}$ values of drained water, which fell within the normal range, except in the SP/C-1.1 treatment, which was significantly lower than the SP/TS-1.5 treatment on a single date, likely attributable to a less concentrated nutrient solution in the $\mathrm{SP} / \mathrm{C}$ treatment (Table 5). The $\mathrm{pH}$ of the rockwool effluent was lower than the $\mathrm{pH}$ of the SP effluents. This is likely attributable to the fact that the SP substrate was buffered by the presence of peat amended with limestone.

Higher EC values were observed for SP treatments compared with rockwool with significant differences detected in May and June (Table 6). This may have affected yield in some of the treatments, which had a high level relative to other treatments (Sonneveld and de Kreij, 1999); however, the overall effect is unknown, because the differences were inconsistent in time.

Analysis of the saturated medium extract at the end of the experiment (Fig. 6) revealed that these differences in salinity were mainly attributable to salt accumulation close to the top of the SP substrate, which may be explained by the presence of an immobile zone, surface evaporation, and irrigation pattern phenomena for this substrate (Letourneau, 2009). Statistical analyses revealed some significant differences in EC between the different sawdust-peat substrate treatments. There was a significant trend toward a smaller decrease in the SP/C-0.9 treatment relative to the other sawdust-peat substrate treatments, possibly because less fertilizer was used with this substrate combination and a higher water potential was maintained, resulting in a higher level of denitrification (see Fig. 5C and results on fertilizer use subsequently).

The volume of applied nutrient solution was highest for the SP/TS-1.5 followed by the rockwool and SP/TM treatments and then the two SP/C treatments (Fig. 7). The amount of solution that leached was minimal in the $\mathrm{SP} / \mathrm{C}$ treatments because of their reservoir but also because the SP/C-0.9 treatment showed a smaller amount of applied solution, most likely as a result of reduced plant activity. The SP/TS-1.5 showed the best performance with the lowest level of leaching and the highest amount of solution used by the plants relative to the SP/TM and rockwool treatments (Fig. 7). Compared with the SP/TM treatment, capillary device containers showed a smaller amount of applied nutrient solution $(8.2 \%$ and $31 \%$ less for SP/C-1.1 and SP/C-0.9, respectively), very likely because of the recycling structure integrated in the container. Consequently, the amount of leaching was highest when irrigation was based on solar radiation (rockwool and SP/TM), whereas it was significantly lower for the tensiometer control treatment (SP/TS-1.5) and the capillary device container treatment. Plant nutrient solution uptake was 33\% higher for SP/TS-1.5 than for SP/TM, whereas the ST/C-0.9 treatment had the lowest uptake. A monthly average of 
$0.17 \mathrm{~kg}$ of major and secondary nutrients per plant per month were used for rockwool and $\mathrm{SP} / \mathrm{TS}$ treatments and $\approx 0.11 \mathrm{~kg}$ for the two other SP/C container treatments (see Table 7). The savings for the latter two treatments relate to the fact that the nutrient solution used in the container was less concentrated $\left(2.0 \mathrm{dS} \cdot \mathrm{m}^{-1}\right.$ vs. $2.5 \mathrm{dS} \cdot \mathrm{m}^{-1}$ for other treatments) and that less solution was used for irrigation. This reduction in fertilizer use may represent a decrease of $\approx 290$ to $350 \mathrm{~kg}$ of N/ha relative to the SP/TM treatment and up to $350 \mathrm{~kg}$ of N/ha for the capillary device (SP/C-0.9).

Therefore, with respect to the first hypothesis, our results clearly show that a constant matric potential container design (capillary system) gives similar plant activity (photosynthetic rate and similar growth and yields) to variable irrigation management based on matric potential thresholds. With respect to the second hypothesis, irrigation management using tensiometers reduced leaching and the amount of greenhouse effluents by
$262 \mathrm{~kg} \mathrm{~N} /$ ha compared with the use of timerbased irrigation adjusted to solar radiation for the SP substrate. The constant matric potential devices further reduced the amount of leaching and fertilizer use without a major effect on salt accumulation and provided similar plant activity and crop yield. Finally, with regard to the third hypothesis, it is shown that with appropriate irrigation management using tensiometers, a SP substrate can permit important water and nutrient savings along with similar tomato plant activity and higher yields compared with rockwool with intermittent irrigation.

The findings related to rockwool appear questionable, because the average water content during the growing period is on the low side $\left(0.26 \mathrm{~cm}^{3} \cdot \mathrm{cm}^{-3}\right)$. Indeed, normal water content for rockwool-grown plants ranges from 0.60 to $0.75 \mathrm{~cm}^{3} \cdot \mathrm{cm}^{-3}$ (Papadopoulos et al., 2008). However, the data in Figure 2B clearly indicate that most of the time the water potential was between -0.4 and $-0.8 \mathrm{kPa}$,

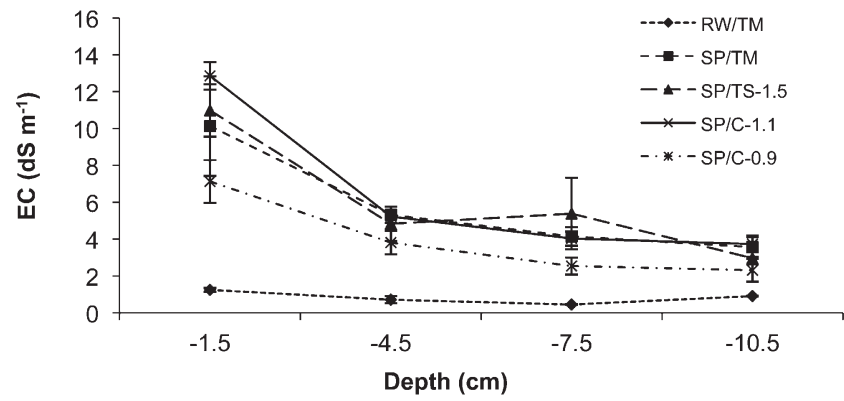

Fig. 6. Electrical conductivity (EC) $( \pm \mathrm{SE})$ in each substrate at different depths.

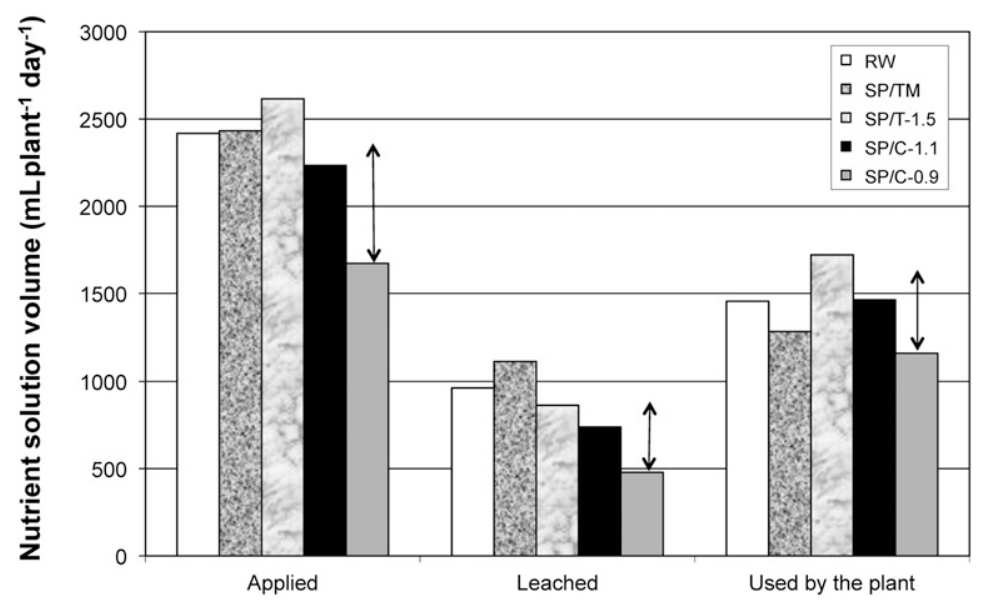

Fig. 7. Water applied, leached, and consumed per plant daily, averaged over the course of the experiment. The arrows indicate the least significant difference at $P=0.05$.

Table 7. Monthly averaged amount of nutrients used for plants in the different treatments at the experimental site.

\begin{tabular}{lcccccc}
\hline Amount of fertilizer/plant/month & Units & RW/TM & SP/TM & SP/TS-1.5 & SP/C-1.1 & SP/C-0.9 \\
\hline Macronutrients & $\mathrm{kg}$ & 0.167 & 0.167 & 0.172 & 0.113 & 0.108 \\
Micronutrients & $\mathrm{g}$ & 2.20 & 2.20 & 2.27 & 1.49 & 1.42 \\
\hline
\end{tabular}

$\mathrm{RW}=$ rockwool; $\mathrm{TM}=$ timer-based irrigation; $\mathrm{SP}=$ sawdust-peat; $\mathrm{TS}=$ tensiometer-based irrigation; $\mathrm{C}=$ constant water potential.

which is a level typical of adequate irrigation. The corresponding water contents were low because the Master dry type of rockwool was used; the water desorption curve (Fig. 3A) for this substrate shows a very sharp decrease in water content with decreasing water potential, which relates to the need to maintain high AFP in the substrate in humid and cloudy environments under commercial operations (see Appendix). The extent to which the rockwoolassociated yields were affected is unknown, because a wet type of rockwool control was not included in the treatments. Some rockwool substrates have performed well at low water contents $\left(0.40 \mathrm{~cm}^{3} \cdot \mathrm{cm}^{-3}\right.$; Blok, 1999), and this dry type has performed better than conventional wet types for several years according to the grower participating in the study. Finally, this type of rockwool might have performed better if a tensiometer-controlled treatment had been applied; this option appears to merit further research.

\section{Conclusions}

Irrigation set points were derived for SP growing medium: $-2.2 \mathrm{kPa}$ in tensiometerbased controlled irrigation in an initial experiment and $-1.5 \mathrm{kPa}$ in a second experiment to achieve maximum photosynthesis. Our results show that a matric potential irrigationcontrolled system may give higher plant activity and yields in the SP medium than in the dry type of rockwool with intermittent irrigation while also causing $22 \%$ less leaching than an irradiance-based approach for the same substrates. Two constant head devices were also tested and allowed nutrient savings of $35 \%$ relative to the other treatments; however, they had a limited effect in terms of improving oxygen and reducing $\mathrm{CO}_{2}$ content in the substrate because of the wetter conditions maintained at the bottom of the container and because of respiration in the bottom reservoir. The capillary devices used with a SP mix resulted in photosynthetic activity similar to that obtained in rockwool and in SP with irrigation adjusted according to solar radiation, but the amount of nutrient solution applied was reduced by $8 \%$ for SP/C1.1 and by $31 \%$ for SP/C-0.9 compared with the rockwool and SP/TM treatments.

\section{Appendix}

Water content in dry type rockwool slabs at a commercial site (Expt. 1). Low water contents measured in the rockwool slab in the study (Expt. 2) were typical of those observed at the commercial site. This is because the water desorption curve of the dry type of rockwool strongly differs from that of conventional rockwool (wet type) available on the market (see Fig. A.1). With regard to the latter, for the same water potential, the volumetric water content would range from 0.80 to $0.90 \mathrm{~cm}^{3} \cdot \mathrm{cm}^{-3}$ according to some studies (Papadopoulos et al., 2008). Measurements taken with horizontally inserted probes, at midheight, over 3 months (7425 points collected over the full $24-\mathrm{h}$ period) in the commercial 


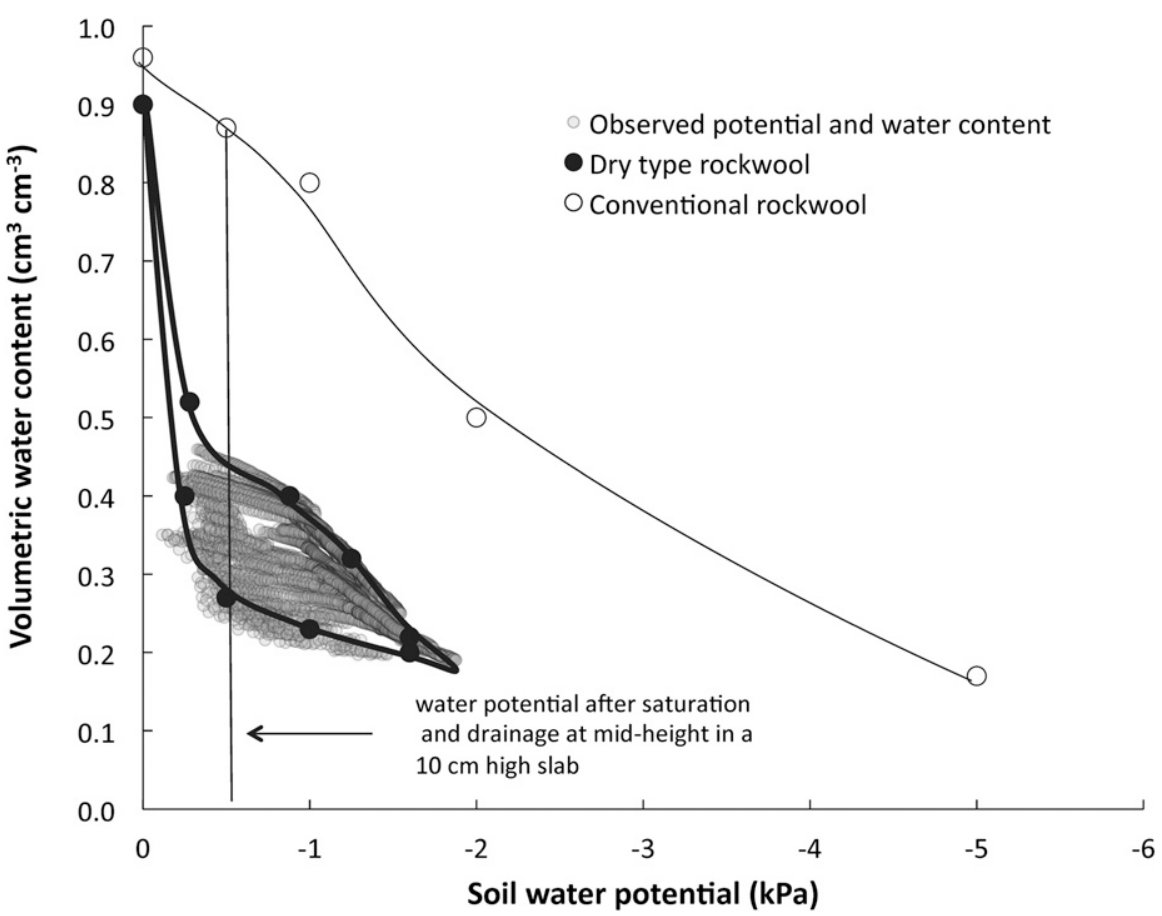

Fig. A1. Water desorption curve of a wet type (a conventional rockwool) and a dry type along with observed volumetric water content and water potential of the substrate at the commercial site from October to January.

greenhouse during Expt. 1 clearly indicated that volumetric water content varied between 0.20 and $0.45 \mathrm{~cm}^{3} \cdot \mathrm{cm}^{-3}$ at slab capacity $(-0.5 \mathrm{kPa})$. The data are consistent with the independently measured water desorption curve of the substrate (see Fig. A.1) and the measured values shown in Figure 3A. All measured values in the commercial greenhouse were within the theoretical range of maximum and minimum volumetric water content values, that is, they were within the hysteresis loop of the water desorption curve, clearly showing the strong hysteresis effect observed for this type of rockwool.

\section{Literature Cited}

Adamson, R.M. and E.F. Maas. 1971. Sawdust and other soil substitutes and amendments in greenhouse tomato production. HortScience 6:397-399.

Adamson, R.M. and E.F. Maas. 1976. Amount and kind of growth media in soilless greenhouse tomato production. HortScience 11:212-213.

Allaire, S.E., J. Caron, C. Ménard, and M. Dorais. 2005. Potential replacements for rockwool as growing substrate for greenhouse tomato. Can. J. Soil Sci. 85:67-74.

Ayari, O., M. Dorais, and A. Gosselin. 2000. Daily variations of photosynthetic efficiency of greenhouse tomato plants during winter and spring months. J. Amer. Soc. Hort. Sci. 125:235-241.

Bégin, G. 2008. Potentiel d'utilisation du bran de scie comme substrat de culture pour la tomate de serre: Phytotoxicité, croissance et productivité. Mémoire de maitrise. Université Laval, Québec, Canada.

Bilderback, T.E. and W.C. Fonteno. 1987. Effects of container geometry and media physical properties on air and water volumes in containers. J. Environ. Hort. 5:180-182.

Blok, C. 1999. Air/water management in rockwool slabs. Acta Hort. 481:79-88.
Dorais, M., C. Ménard, and G. Bégin. 2007. Risk of phytotoxicity of sawdust substrates for greenhouse vegetables. Acta Hort. 761:589-594.

Dorais, M. and S. Pepin. 2011. Soil oxygenation effects on growth, yield and nutrition of organic greenhouse tomato crops. Acta Hort. 915:91-99.

Frenz, F.W. and P. Lechl. 1981. The influence of different water suctions on yield and water requirements of tomatoes, cucumbers, radishes and lettuce in greenhouses. Acta Hort. 119:323-331.

Gruda, N. and W.H. Schnitzler. 2004. Suitability of wood fiber substrate for production of vegetable transplants. I. Physical properties of wood fiber substrates. Sci. Hort. 100:309-322.

Guttormsen, G. 1974. Effects of root medium and watering on transpiration, growth and development of glasshouse crops. II. The relationship between evaporation pan measurements and transpiration in glasshouse crops. Plant Soil 40:461-478.

Haynes, R.J. and K.M. Goh. 1978. Evaluation of potting media for commercial nursery production of container-grown plants. N. Z. J. Agr. Res. 21:449-456.

Jobin, P., J. Caron, P.Y. Bernier, and B. Dansereau. 2004. Impact of two hydrophilic acrylic-based polymers on the physical properties of three substrates and the growth of Petunia $\times$ hybrida 'Brillliant Pink'. J. Amer. Soc. Hort. Sci. 129: 449-457.

Johnstone, P.R., T.K. Hartz, M. LeStrange, J.J. Nunez, and E.M. Miyao. 2005. Managing fruit soluble solids with late-season deficit irrigation in drip-irrigated processing tomato production. HortScience 40:1857-1861.

Caron, J., D.E. Elrick, R. Beeson, and J. Boudreau. 2005. Defining critical capillary rise properties for growing media in nurseries. Soil Sci. Soc. Amer. J. 69:783-793.

Caron, J., P. Morel, L.M. Rivière, and G. Guillemain. 2010. Growth limitations with large particles in growing media: Physical and methodological issues. Can. J. Soil Sci. 90:481-494.

Caron, J., L.E. Parent, D.E. Elrick, and R. Naasz. 2008. Physical properties of organic soils and growing media: Water and air storage and dynamics. In: Carter, M.R. (ed.). Soil sampling and methods of analysis. CRC Press, Boca Raton, FL.

Caron, J., L.-M. Rivière, S. Charpentier, P. Renault, and J.-C. Michel. 2002a. Using TDR to estimate hydraulic conductivity and air entry in growing media and sand. Soil Sci. Soc. Amer. J. 66:373383.

Caron, J., R. Beeson, J. Boudreau, and J. Haydu. $2002 \mathrm{~b}$. Irrigation in the nursery: Saving water while improving plant growth. Am. Nurse 196: 32-34.

Conseil des Productions Végétales du Québec. 1988. Détermination de la conductance d'un sol. Méthode SS-1. Méthodes d'analyse des sols, des fumiers et des.

De Boodt, M. and N. de Waele. 1968. Study on the physical properties of artificial soils and the growth of ornamental plants. Pedologie (Gent) $3: 275-300$.

Desbiens, M.-C. 2004. Développement d'un substrat de remplacement à la laine de roche pour la culture de la tomate de serre (Lycopersicon esculentum Mill. cv Tradiro). Mémoire. Université Laval.

Dorais, M. 2008. Organic production of vegetables: State of the art and challenges. Can. J. Plant Sci. 87:1055-1066.

Dorais, M., J. Caron, G. Bégin, A. Gosselin, L. Gaudreau, and C. Ménard. 2005. Equipment performance for determining water needs of tomato plants grown in sawdust based substrates and rockwool. Acta Hort. 691:293-304.
Juneau, V., J. Caron, C. Martinez, V. Gravel, and S. Allaire. 2006. Growing media, greenhouse tomato yield and Pythium root rot. Can. J. Soil Sci. 86:501-512.

Kostov, O., V. Rankov, G. Atanacova, and J.M. Lynch. 1991. Decomposition of sawdust and bark treated with cellulose decomposing microorganisms. Biol. Fertil. Soils 11:105-110.

Lemaire, F., A. Dartigues, L.M. Rivière, S. Charpentier, and P. Morel. 2003. Cultures en pots et conteneurs. INRA Editions, Institut National de la Recherche Agronomique, Paris, France.

Lemay, I. 2006. Régies d'irrigation et rendement de la tomate de serre (Lycopersicon esculentum Mill.) en mélange sciure-tourbe. MSc thesis, Soil Science and Agrifood Engineering Department.

Letard, M., P. Evrard, and B. Jeannequin. 1995. Maitrise de l'irrigation fertilisante. Tomate sous serre et abris en sol et hors sol. Les éditions du Ctifl., Paris, France.

Letourneau, G. 2009. Mouvement de sels en substrats organiques pour la culture de la tomate de serre. MSc thesis, Soil Science and Agrifood Engineering Department, Laval University, Quebec, Canada.

Lieth, J.H. and D.W. Burger. 1989. Growth of chrysanthemum using an irrigation system controlled by soil moisture tension. J. Amer. Soc. Hort. Sci. 114:387-392.

Mahajan, G. and K.G. Singh. 2006. Response of greenhouse tomato to irrigation and fertigation. Agr. Water Manage. 84:202-206.

Michelakis, N.G. and K.S. Chartzoulakis. 1988. Water consumptive use of greenhouse tomatoes as related to various levels of soil water potential under drip irrigation. Acta Hort. 228:127-135.

Morel, P., L. Poncet, and L.M. Rivière. 2000. Un point sur les supports de culture horticoles. INRA, Paris, France.

Naasz, R., J. Caron, J. Legault, and A. Pichette. 2009. Efficiency factors for bark substrates: 
Biostability, aeration, or phytotoxicity. Soil Sci. Soc. Amer. J. 73:1-12.

Norrie, J., M.E.D. Graham, J. Charbonneau, and A. Gosselin. 1995. Impact of irrigation management of greenhouse tomato: Yield, nutrition, and salinity of peat substrate. Can. J. Plant Sci. 75:497-503.

Örlander, G. and K. Due. 1986. Location of hydraulic resistance in the soil-plant pathway in seedlings of Pinus sylvestris L. grown in peat. Can. J. For. Res. 16:115-123.

Papadopoulos, A.P., U. Saha, X. Hao, and S. Khosla. 2008. Irrigation management in greenhouse tomato production on rockwool. Acta Hort. 779:521-528.

Paquet, J.M., J. Caron, and O. Banton. 1993. In situ determination of the water desorption characteristics of peat substrates. Can. J. Soil Sci. 73: 329-339.

Rochette, P., R.R. Simard, N. Ziadi, M.C. Nolin, and A.N. Cambouris. 2004. Atmosphere composition and $\mathrm{N}_{2} \mathrm{O}$ emissions in soils of contrasting textures fertilized with anhydrous ammonia. Can. J. Soil Sci. 84:339-352.

SAS Institute, Inc. 2008. The SAS system for Windows, Release 9.2. SAS Institute, Inc., Cary, NC.

Smith, K.A. and R.J. Dowdell. 1974. Field studies of the soil atmosphere 1. Relationships between ethylene, oxygen, soil moisture content and temperature. J. Soil Sci. 25:217 230.

Sonneveld, C. and C. de Kreij. 1999. Response of cucumber (Cucumis sativus L.) to an unequal distribution of salts in the root environment Plant Soil 209:47-56.

Starck, J.R. and B. Okruszko. 1984. The effect of nitrogen on yield of greenhouse tomatoes grown in peat, pine bark and sawdust. Acta Hort. 145:74-80.

Topp, G.C., J.L. Davis, and A.P. Annan. 1980. Electromagnetic determination of soil water content: Measurements in coaxial transmission lines. Water Resour. Res. 16:574-582.

Topp, G.C. and W. Zebchuk. 1979. The determination of soil-water desorption curves for soil cores. Can. J. Soil Sci. 59:19-26.

Waister, P.D. and J.P. Hudson. 1970. Effects of soil moisture regimes on leaf water deficit, transpiration and yield of tomatoes. J. Hort. Sci. 45: 359-370.

Webb, R.A. 1972. Use of the boundary line in the analysis of biological data. J. Hort. Sci. 47: 309-319.

Webster, C.P. and K.W.T. Goulding. 1989. Influence of soil carbon content on denitrification from fallow land during autumn. J. Sci. Food Agr. 49:131-142.

Xu, H.-L., L. Gauthier, and A. Gosselin. 1995. Effects of fertigation management on growth and photosynthesis of tomato plants grown in peat, rockwool and NFT. Sci. Hort. 63:1120. 